\title{
Encontrar filosofia(s) e infância(s)
}

\author{
Paula Ramos de Oliveira \\ Denis Domeneguetti Badia \\ Cesira Elisa de Fávari \\ Ediléia Pereira Sônego²
}

\begin{abstract}
Resumo: Este texto busca pensar algumas possibilidades de unir "filosofia" e "infância" em dois momentos: o primeiro é teórico e o segundo traz propostas de trabalho em torno da temática. Na parte teórica, apresentamos a proposta de Matthew Lipman que tornou possível levar a filosofia às crianças. Na sequência apontamos as contribuições de outras áreas para pensar a infância: em P. Ariès vemos que o conceito de infância nem sempre existiv; Postman nos indica que vivemos o processo de adultização das crianças e o de infantilização dos adultos; Clarice Cohn mostra, com seu estudo dos Xikrin, que o conceito de infância pode não existir em certas sociedades; Walter Kohan pensa o tempo como intensidade (aión) e não somente como cronologia (chrónos), nos remetendo a um novo olhar para a infância; Larrosa trata da alteridade da infância, e da necessidade de entendê-la como um enigma. Por fim, olhamos para a criança como aquela que filosofa e que olha para a filosofia. Na parte dois apresentamos três atividades (carta, fotos, poesia, pintura, e fragmentos de Heráclito) propostas como experiências que tornem possível problematizar as relações entre filosofia e infância.
\end{abstract}

Palavras-chave: filosofia; infância; crianças.

Resumen: Este texto trata de pensar en algunas posibilidades para unir "filosofía" e " infancia" en dos etapas: la primera es teórica y la segunda trae propuestas de trabajo en torno del tema. En la parte teórica, se presenta la propuesta de Matthew Lipman, que hizo posible llevar la filosofía a los niños. Inmediatamente, señalamos las contribuciones de otras áreas para pensar la infancia: en P. Ariès entendemos que el concepto de infancia no siempre ha existido; Postman nos dice que vivimos un proceso de adultización de los niños y de infantilización de los adultos; Clarice Cohn muestra, con su estudio de los Xikrin, que el concepto de la infancia puede no existir en algunas sociedades; Walter Kohan piensa el tiempo como intensidad (aión), y no sólo como la cronología (chrónos), refiriéndonos a una nueva mirada a la infancia; Larrosa trata de la alteridad de la infancia, y de la necesidad de entenderla como un rompecabezas. Por fin, nos fijamos en el niño como el que filosofa y mira la filosofía. En la segunda parte se presentan tres actividades (carta, fotos, poesía, pintura, y los fragmentos de Heráclito) propuestas como experiencias que hacen que sea posible discutir la relación entre filosofía e infancia.

Palabras clave: filosofía; infancia; niños.

2Paula Ramos e Denis Badia são professores do Programa de Pós-Graduação em Educação Escolar e do Departamento de Ciências da Educação, da Faculdade de Ciências e Letras de Araraquara (FCL-UNESP-CAr). Cesira Fávari e Edileia Sônego são doutorandas do mesmo programa.

Revista Digital de Ensino de Filosofia - Santa Maria - vol.2., n.2 - jul./dez. 2016. 


\section{Introdução}

Que interesse pode ter o tema "Filosofia(s) e infância(s)" como conteúdo programático das aulas de Filosofia no Ensino Médio? Começaríamos afirmando que tudo o que diz respeito ao humano interessa à filosofia e que a busca por compreendê-lo está inevitavelmente ligada a como pensamos a experiência humana. É a partir desta perspectiva que apresentaremos alguns modos de unir filosofia e infância.

\section{PARTE 1: Filosofia(s) e infância(s)}

\section{A filosofia encontra as crianças, as crianças fazem filosofia: a proposta de Filosofia para Crianças de Matthew Lipman}

A filosofia, via-de-regra, é considerada como sendo coisa de adulto e, aliás, não de qualquer adulto. Paira no ar uma aura de que é matéria para os que são muito inteligentes, tendo em vista sua complexidade. Mas quem assim afirma corre o risco de ficar fora da filosofia, justamente por não fazer uso da problematização tão cara e necessária a qualquer prática filosófica. Há inúmeras concepções de filosofia, assim como são muitas as maneiras possíveis de praticá-la. E tudo isso já é filosofia!

Epicuro (341 a.C. - 270 a.C.) inicia sua Carta sobre a Felicidade (a Meneceu) dizendo:

Que ninguém hesite em se dedicar à filosofia enquanto jovem, nem se canse de fazê-lo depois de velho, porque ninguém jamais é demasiado jovem ou demasiado velho para alcançar a saúde do espírito. Quem afirma que a hora de dedicar-se à filosofia ainda não chegou, ou que ela já passou é como se dissesse que ainda não chegou ou que já passou a hora de ser feliz. Desse modo, a filosofia é útil tanto ao jovem quanto ao velho: para quem está envelhecendo sentir-se rejuvenescer através da grata recordação das coisas que já se foram, e para o jovem poder envelhecer sem sentir medo das coisas que estão por vir; é necessário, portanto, cuidar das coisas que trazem a felicidade, já que, estando esta presente, tudo temos, e, sem ela, 
tudo fazemos para alcançá-la. (EPICURO, 2002, p. 21).

Montaigne (1533-1592) também afirmou:

\begin{abstract}
É espantoso que as coisas tenham chegado, em nosso século, ao ponto de a Filosofia ser até para as pessoas inteligentes algo vão e fantástico, considerado de nenhuma utilidade e de nenhum valor tanto para a opinião geral como para a prática. Creio que a causa disso são essas sutilezas que ocuparam suas avenidas. É grande erro pintá-la como inacessível às crianças, e de semblante carrancudo, austero e terrível: quem a mascarou com esse falso rosto pálido e medonho? Não há nada mais alegre, mais jovial, divertido, e por pouco não digo galhofeiro. Ela não prega senão a festa e os bons momentos. Um semblante triste e abatido mostra que não é esta a sua morada. (MONTAIGNE, 2010, p. 74, grifos nossos)
\end{abstract}

Entretanto, foi apenas com Matthew Lipman (1923-2010) que a filosofia chegou até as crianças, pois esse filósofo norte-americano sistematizou uma proposta de ensino dessa disciplina que ficou conhecida como "Filosofia para Crianças". Lipman acreditava que uma verdadeira revolução poderia ocorrer na Educação com a introdução da filosofia desde os primeiros anos escolares. Tal proposta - que se caracteriza por ser filosófica-educacional - foi motivada por sua experiência como professor de Lógica, na Universidade de Colúmbia, quando percebeu que seus alunos não sabiam verdadeiramente ler, escrever e calcular. Pensou que esse problema deveria ser combatido desde a primeira infância. Mas como levar a Lógica para as crianças?

Resolveu então escrever o que ficou conhecido como novelas filosóficas abrangendo, ao longo do tempo, todos os anos escolares, incluindo a Educação Infantil. No Brasil foram traduzidas as seguintes novelas: Issao e Guga (Filosofia da natureza); Pimpa (Filosofia da linguagem); A Descoberta de Ari dos Telles (Lógica); e Luísa (Ética). Além disso, temos traduzida uma novela chamada Rebeca, para a Educação Infantil, escrita por Ronald Reed (falecido em 1998). Todas elas são acompanhadas por um manual do Revista Digital de Ensino de Filosofia - Santa Maria - vol.2., n.2 - jul./dez. 2016. 
professor. Lipman escreveu também Mark (Filosofia política) e Suki (Estética), dirigidas ao Ensino Médio, e ainda Elfie que trata da comunidade de investigação - metodologia que Lipman elaborou para a prática filosófica que ocorre a partir das novelas.

A comunidade de investigação (ideia inspirada em Charles S. Pierce, que pensou nestes dois conceitos em relação aos cientistas) é algo que vai sendo construído em cada turma de alunos e é composta por uma dimensão ética e por uma cognitiva. Por ser assim caracterizada pode variar o tempo decorrente para que uma comunidade se forme (e, aliás, sempre continuará em "estado" de formação).

Do ponto de vista cognitivo o que se espera é que com o diálogo filosófico sejam desenvolvidas as habilidades de quatro conjuntos maiores chamados de mega-habilidades (de raciocínio, de investigação, de formação de conceitos e de tradução). Pretende-se assim que os alunos desenvolvam o raciocínio crítico e criativo, chegando ao pensamento multidimensional que é, a um só tempo, crítico, criativo e cuidadoso.

No que diz respeito à dimensão ética, podemos destacar que há certos procedimentos na aula que implicam essa dimensão, tais como saber ouvir o outro, esperando a sua vez de falar, e dar razões ao que argumenta, apreendendo a pensar criticamente sobre o seu próprio pensamento (atitude autocorretiva).

Nas aulas existem algumas etapas a serem seguidas: leitura individual ou coletiva das novelas, levantamento de questões (colocando em cada uma a autoria), agrupamento das questões por temas e a discussão que normalmente começa com a organização dos assuntos. O professor é um facilitador do diálogo e mantém uma relação horizontal com seus alunos, fazendo também parte da comunidade de investigação.

As novelas filosóficas mostram personagens que servem como modelo do que Lipman espera dos alunos e do professor na discussão filosófica. Cada criança tem uma especificidade em seu pensamento que contribui com o coletivo. Uma é mais empírica, a outra mais analítica, outra mais sintética e assim por diante. 
Para Lipman as crianças, assim como os filósofos, têm a capacidade de se admirar com o mundo, e a filosofia, segundo essa proposta, é eminentemente algo que se faz, que se pratica, é o próprio filosofar. Na ideia de Filosofia para Crianças há, portanto, uma concepção de filosofia e outra de criança, além de uma afirmação (teórica e prática) de que crianças podem e devem filosofar. Vemos assim que conhecer Filosofia para Crianças é entrar em contato com um modo de filosofar que pode acontecer em qualquer idade.

A ideia de Filosofia para Crianças foi divulgada e praticada em diversos países e, como era de se esperar, ganhou novos contornos teórico e prático. Walter Omar Kohan, que teve sua tese defendida sob a orientação de Lipman, é hoje um expoente na área e nos ajuda a pensar e aprofundar questões relativas à educação, filosofia e infância, através de outro referencial teórico, marcado dominantemente pela Filosofia Francesa Contemporânea, em especial com Deleuze e Foucault. No próximo tópico comentaremos acerca de como a filosofia pode pensar a infância.

\section{A filosofia pensa a(s) infância(s)}

Várias são as áreas que estudam a infância. Podemos destacar a Sociologia da infância, a História da infância, a Antropologia da criança, a Psicologia da infância, a Educação da infância, e a Filosofia da infância. Todas elas colaboram para apontar aspectos que merecem ser considerados na compreensão do que convencionamos chamar Infância. Não nos enveredaremos, obviamente, por todos esses caminhos, mas procuraremos nos atentar a alguns aspectos do tema.

Em primeiro lugar, cumpre-nos considerar que há uma visão dominante de infância que praticamente a toma como sinônimo de criança, tendo em vista que é compreendida em termos cronológicos e, portanto, como uma etapa da vida humana que se inicia com o nascimento.

Porém, estudos nos mostram que tal visão pode ser problemática. Um dos mais importantes e conhecidos é o de Philippe Ariès (1914-1984), que em sua obra História Social da Criança e da Família (1981), defende que o Revista Digital de Ensino de Filosofia - Santa Maria - vol.2., n.2 - jul./dez. 2016. 
sentimento de infância é uma construção do Ocidente que surge entre os séculos XVI e XVII e que, portanto, nem sempre existiu. Anteriormente as crianças passavam da fase em que mereciam muitos cuidados diretamente para uma vida junto aos adultos. De fato, eram adultos em miniaturas. Um sentimento de infância vai se revelando quando as crianças começam a ser "paparicadas", mimadas pelos adultos, e inicia a construção de espaços específicos para as crianças, como a escola e o lar.

Outro estudo importante e bastante conhecido é o de Neil Postman (1931-2003), com sua obra O desaparecimento da infância (1999). Para o autor há diversos indícios (tais como erotização precoce e envolvimento em crimes) de que estamos vivendo em um tempo que produz crianças "adultizadas" e adultos infantilizados.

Assim, se com Ariès entendemos que a infância nem sempre existiu, com Postman temos uma perspectiva que teme o desaparecimento da infância.

A Antropologia da criança é um outro âmbito do conhecimento que traz também uma contribuição muito importante. Falamos em antropologia da criança e não da infância! Se, como já vimos, Philippe Ariès constata que a ideia de infância é uma "construção" social e histórica do mundo ocidental, então a infância é um modo "particular" e não "universal" de pensar a criança. A Antropologia da criança vai nos mostrar que em outras culturas e sociedades, a ideia de infância pode não existir ou então ser formulada de outros modos. O que é ser criança, ou quando acaba a infância, pode ser pensado de maneira diferente dependendo do contexto cultural.

Poderemos ilustrar isso através do trabalho de Clarice Cohn intitulado Crescendo como um xikrin. Uma análise da infância e do desenvolvimento infantil entre os Kayapó-Xikrin do Bacajá (2000), uma etnia indígena do Pará. A pesquisadora mostra (2000 e 2005) que para os xikrin, o corpo de um novo ser humano vai sendo criado durante a gestação, gradativamente, por meio das relações sexuais. Não há, portanto, um momento único de concepção, seguido da formação do corpo, mas uma formação contínua. Como mais de um homem pode contribuir para essa formação, o bebê pode ter mais de um 
pai, que será reconhecido e reconhecerá sua paternidade. A formação do corpo durante a gestação cria um laço corpóreo entre o bebê e seus genitores que durará a vida toda.

Enfim, o belíssimo estudo de Clarice Cohn vai mostrar que entre os xikrin se é criança até o momento em que o menino ou a menina passam a ter uma criança que é sua. Será a quantidade de filhos que levará esses novos adultos a mudar de "categoria de idade", até a velhice, que os xikrin dizem ser o momento em que não se tem mais filhos, ou de um modo poético, como assinala a pesquisadora, quando seus filhos e netos passam a ter filhos por ele. Esse exemplo demonstra a complexidade da questão infância-criança em outros contextos culturais.

Um outro antropólogo, Clifford Geertz (1926-2006), vai dizer que uma das finalidades dos estudos antropológicos é ser uma espécie de "arquivo universal" ou de "catálogo geral" das alternativas humanas de existência. A Antropologia procura colocar ao alcance dos homens as várias respostas existenciais que os vários grupos socioculturais deram pelo mundo afora. A antropologia é um saber, um conhecimento ou uma literatura que não está alinhada com as verdades absolutas, mas com as interpretações relativas. A pesquisa antropológica realizada por Clarice Cohn vai nos mostrar que as crianças xikrin constroem grande parte das relações sociais em que se engajarão durante a vida... A criança, segundo a autora, não é alocada em um sistema de relações anteriores a ela e reproduzido eternamente; elas desempenham um papel ativo na sociedade. Para a Antropologia da criança, a diferença entre as crianças e os adultos não é quantitativa, mas qualitativa, isto é, a criança não sabe menos, ela sabe outra coisa. A criança é vista como um sujeito social, ativo e atuante.

Temos então pelo menos duas ideias importantes: 1) o conceito de infância pode nunca existir em uma sociedade; e 2) a criança não deve ser vista como aquela que ainda não é algo que esperamos que ela seja.

Esta segunda ideia nos leva aos três mitos que Walter Kohan problematiza. São eles: 
tempos antigos, a partir do dispositivo socráticoplatônico da pergunta que sabe de antemão o valor das respostas, que propõe uma estratégia educativa para a transformação da pólis, e se atualiza em nossos tempos nos modos dos programas para a formação cidadã ou a educação para a democracia. * o mito antropológico da infância como a primeira etapa da vida humana; em uma visão da vida humana organizada sob a lógica de um tempo cronológico, sucessivo, consecutivo e em progressão para o melhor, que também tem raízes antigas e desdobra todo o seu esplendor nas contemporâneas psicologias da aprendizagem. * o mito filosófico das ausências, negatividades ou imperfeições que se escondem, a partir da etimologia, em uma série de termos como a própria 'infância', o 'estrangeiro', a 'ignorância' e, de uma forma mais geral, o 'estranho', o 'outro', o que não habita o 'nosso mundo'. ${ }^{3}$

Walter Kohan (2004), em contraposição ao modo dominante de pensar a infância como uma etapa de vida, como cronologia, busca pensá-la com Agamben e Deleuze. Em Agamben a infância é uma condição da experiência humana. Desse modo, Kohan propõe que ampliemos os "horizontes da temporalidade".

O "tempo", em grego clássico, é designado por mais de uma palavra: chrónos (tempo sucessivo), kairós (medida, proporção, temporada, momento crítico, oportunidade) e aión (intensidade, duração). Ao lado da dimensão cronológica - ou seja, sem excluí-la - Kohan ${ }^{4}$ nos mostra que a infância tem também uma dimensão aiônica e com ela surgem novos sentidos da/para a infância.

No fragmento 52 de Heráclito pode-se ver a ligação de aión com o poder e com a infância:

Ele diz que 'aión é uma criança que brinca (literalmente, criançando), seu reino é o de uma criança.' Há uma dupla relação afirmada: tempo infância(aión- paîs) e poder-infância (basileíepaîs). Este fragmento parece indicar, entre outras coisas, que o tempo da vida não é apenas

\footnotetext{
3 KOHAN, 2007, p 09-10.

42004 , p. 54.

Revista Digital de Ensino de Filosofia - Santa Maria - vol.2., n.2 - jul./dez. 2016.
} 
questão de movimento numerado e que esse outro modo de ser temporal parece com o que uma criança faz. Se uma lógica temporal segue os números, outra brinca com os números. ${ }^{5}$

Assim, o fragmento sugere que a criança não vive apenas uma etapa de vida uma cronologia, mas sim um tempo que é uma "intensidade da duração". No reino infantil há uma força infantil que é o tempo aiônico.

Quanto à Deleuze também temos, ainda segundo Kohan, a distinção de dois modos de temporalidade: a história e o devir:

\begin{abstract}
A história não é experiência, mas o conjunto de condições de uma experiência e de um acontecimento que tem lugar fora da história.[...] De um lado está o contínuo: a história, chrónos, as contradições e as maiorias; do outro lado o descontínuo: o devir, aión, as linhas de fuga e as minorias. Por isso, o devir é sempre minoritário. 6
\end{abstract}

Deste modo, do ponto de vista de uma micropolítica, a infância é acontecimento, experiência, revolução, resistência, criação e interrompe a história. Pensar a infância como devir amplia, assim, os seus sentidos de muitas maneiras. Ao lado de uma Educação da infância teríamos uma espécie de infância da Educação, e também fica possível pensar uma infância da filosofia ao lado ou em uma Filosofia da infância.

Abrir-se a novos sentidos da/para a infância é assumir que queremos encontrar novas faces das crianças e da infância, que não as dominamos e nem as controlamos, que elas trazem para nós algo de enigmático.

Tal movimento insere-se na contramão de uma visão hegemônica das crianças e da infância. É que cada vez mais, diz Larrosa, temos instituições e setores que se dedicam às crianças. Os estudos também se multiplicam. Nós adultos, pesquisadores ou não, vivemos com a sensação de tudo saber sobre elas, as crianças, que são nossos "objetos" de estudo. Também o fato de já termos sido crianças um dia nos dá essa ilusão de que as controlamos, seja pelo saber ou pelo poder - ainda que não muito percebido, ainda que utilizado com pretensões educacionais e/ou boas intenções. Mas eis então

5 KOHAN, 2004, p. 54-55.

6 KOHAN, 2004. p. 62.

Revista Digital de Ensino de Filosofia - Santa Maria - vol.2., n.2 - jul./dez. 2016. 
que surge um paradoxo: distanciamo-nos das crianças quando nos aproximamos delas objetivando-as, retirando delas sua condição de sujeito. Ou seja, uma certa maneira de nos aproximar pode, de fato, provocar um distanciamento.

É a partir desta perspectiva que Jorge Larrosa (2003) apresenta uma imagem e uma contra-imagem da infância. A imagem (do totalitarismo)

é o rosto daqueles que, quando olham para uma criança, já sabem de antemão, o que vêem e o que têm que fazer com ela. A contra-imagem poderia resultar da inversão da direção do olhar: o rosto daqueles que são capazes de sentir sobre si mesmos o olhar enigmático de uma criança, de perceber o que, nesse olhar, existe de inquietante para todas as certezas e seguranças e, apesar disso, são capazes de permanecer atentos a esse olhar e de se sentirem responsáveis diante de sua ordem: deves abrir para mim, um espaço no mundo, de forma que eu possa encontrar um lugar e elevar minha voz!?

Para Larrosa, assim, a infância é um outro ${ }^{8}$ e isso significa que ela deve ser vista não pelo que já sabemos dela, mas sim como o que ainda não foi capturado pelos nossos saberes e pelos nossos poderes. Devemos acolher a novidade que a infância, tal como um nascimento, traz. Eis a possibilidade de um verdadeiro encontro com ela: quando estamos bem diante do enigma que ela representa.

\section{Encontrar filosofia e encontrar infância}

Vemos que os encontros possíveis entre Filosofia e as crianças ou entre Filosofia e infância dependem da forma com que a Filosofia olha a criança e a infância. Isso sabemos. Mas também depende do olhar da criança e da infância para nós e para a Filosofia. Isso talvez saibamos menos.

"O tempo nunca acaba, nem quando a gente morre."; "Se o tempo ia parar de passar o mundo ia parar de rodar, né?"; "Sabe que a minha bola

\footnotetext{
7 LARROSA, 2003, p. 192.

8 2003, p. 184.

Revista Digital de Ensino de Filosofia - Santa Maria - vol.2., n.2 - jul./dez. 2016.
} 
preferida é o mundo? "Tem muito trabalho para fazer o mundo."9 Aos três anos Tomé levanta sua voz e a escutamos! Escutar essas vozes é colocar frente a frente Filosofia e Infância. A Filosofia olha a infância. A infância olha a Filosofia. A Filosofia é infância. A infância é Filosofia. Há muitas Filosofias na infância. Há muitas infâncias na Filosofia.

\section{PARTE 2: ENCONTROS ENTRE FILOSOFIA E INFÂNCIA}

Por que pensar a infância? Por que pensar a Filosofia? Pensar a infância é fazer Filosofia? Fazer Filosofia é pensar uma infância? Quando que a Filosofia e a infância deixam de ser singulares e tornam-se plurais? E se a Filosofia e a infância admitirem apenas o plural? Quais as implicações disto? Por que pensar a infância na Filosofia? Por que pensar a Filosofia na infância? Quais os caminhos para pensarmos infância(s) e filosofia(s)?

Vemos três modos de unir essas duas palavras: a Filosofia tratando da infância, a Filosofia/o filosofar como infância, e a infância que faz filosofia. As propostas de trabalho que apresentamos procuram, de maneiras distintas, discutir os dois primeiros.

\section{ETAPA 1: Foto-grafias, Filosofias e infâncias}

Trazer a fotografia para as aulas de Filosofia pode ser um exercício e uma experiência bastante interessante, uma vez que, entre outras coisas, sugere-se como um olhar específico que recorta e registra um momento. A obra "Câmera clara", de Roland Barthes'0 (1915-1980), mostra o caminho que este autor percorreu para pensar a fotografia, sugerindo dois conceitos para essa análise: o studium e o punctum. Esses conceitos mostram que uma foto pode interessar pelo que nos revela enquanto um "saber" (cultural ou técnico; por exemplo, um elemento histórico que nela está presente, tal como uma guerra ou uma luminosidade que o fotógrafo retratou) ou enquanto uma

\footnotetext{
9 ANTUNES; ANTUNES, 2006, p. 18, 51, 31 e 10 respectivamente.

10 BARTHES, Roland. A Câmara Clara: nota sobre a fotografia. Tradução de Júlio Castoñon Guimarães. Rio de Janeiro: Nova Fronteira, 1984.

Revista Digital de Ensino de Filosofia - Santa Maria - vol.2., n.2 - jul./dez. 2016.
} 
espécie de "fisgada" (por exemplo, um detalhe minúsculo que nos chama a atenção e que nos faz olhar de um jeito diferente para o conjunto). Propomos aqui que as fotos sejam oferecidas como exercícios de escrita e de leitura, pois tanto é escrita de mundo e, portanto, tem autoria, quanto ao ser compartilhada faz-se também como leitura.

Com uma antecedência de aproximadamente duas semanas, o professor pede aos alunos (e essa aula já é o início dessa atividade I) que tirem uma "foto artística" (se revelada, um bom tamanho é o de $15 \times 25$ ) para uma aula que irá ocorrer posteriormente. Sugira a leitura da obra de Roland Barthes, mas garanta a apresentação dos dois conceitos acima. Em seguida, defina "foto artística" simplesmente como uma imagem que nos "dê o que pensar e sentir", que seja significativa de um "olhar" de algo que merece ser registrado e compartilhado justamente por ter, para o seu autor, um punctum qualquer. A seguir, apresentamos trechos de uma carta, escrita por Cesira Elisa de Fávari'1', para ser lida para os alunos como um exemplo de leitura que ocorreu a partir de um punctum visto por sua autora no livro de Roland Barthes. Sugerimos que a foto abaixo seja mostrada apenas após a leitura e que o professor reforce o pedido da foto, sem que haja discussão da carta, para que essa leitura se torne pensamento e sentimento em cada um.

"Olá Ernest. Sou Cesira, tenho 26 anos e, apesar de já ter terminado o último ano do colegial há um bom tempo, ainda sou estudante. Quando era criança, mais ou menos da sua idade, vivia perguntando para meu pai quando é que se parava de estudar. Sua resposta me desanimava um pouco, pois parecia que esse negócio de ficar na escola não teria fim. A verdade é que eu não gostava de acordar cedo. [...]

Imagino que você não deve dar tanto trabalho aos seus pais para ir à escola, pois sempre vejo você na sala de aula com uma expressão serena. Não são apenas seus olhos e o leve sorriso que me chamam a atenção. Observo também a sua amiga que senta atrás de você. Apesar de olhar para

11 FÁVARI, Cesira Elisa de. Carta a Ernest. In: KOHAN, Walter Omar; OLIVEIRA, Paula Ramos de (orgs). Biopolítica, escola e resistência: infâncias para a formação de professores. Vol. 2. Campinas: Alínea, 2012. p.279-281. 
a minha direção, olha sem me ver, como que por uma fração de segundo ela não tivesse notado na verdade minha presença. Seja lá o que estava a escrever ou ler deveria ser muito interessante. Como ela se chama? Vocês brincam muito no intervalo? Nossa! Estou fazendo todas essas perguntas e nem sei se vocês são realmente amigos, apenas fiz uma suposição por sentarem próximos na mesma fileira de carteiras. Vou chamá-la então de sua colega, pois esta é uma palavra que sugere uma aproximação sem ser aproximada demais. Mas me veio em mente nesse exato momento que vocês podem não ser amigos e nem muito menos colegas, mas sim inimigos! Daqueles que puxam nossos cabelos, que nos perseguem no intervalo para pegar nosso lanche ou pior ainda, nos isolar das brincadeiras mais divertidas em que todos participam. [...]

O que vocês têm em cima da carteira são livros? Gosto muito de livros e você? Mas gosto de forma especial de alguns que me mostram o mundo e as coisas de um jeito que nunca antes havia pensado, ou que havia pensado, mas até então não tinha ninguém para compartilhar. É que considero o autor do livro como alguém muito próximo. De alguns gostaria muito de ser amiga, até mesmo daqueles que já morreram.

Já que não há como descobrir o que vocês lêem, vou contar o que atualmente estou lendo. Sei que as crianças ficam impressionadas com a quantidade de páginas dos livros. Então vamos lá: são 175 páginas. Algo que posso dizer para vocês é que pode parecer muito, mas à medida que os anos passam e crescemos, cento e tanto não é um número tão gigantesco assim. Quem escreveu foi Roland Barthes e o livro se chama A Câmara Clara é uma tentativa de descobrir o que é a fotografia em sua essência, ou seja, o que ela tem de mais profundo. Considero este livro interessante Ernest, pelos seguintes motivos: apesar de ter sido escrito há muitos anos tenho a sensação de estar acompanhando o raciocínio do autor no momento da escrita. É como se eu tivesse feito uma viagem no tempo para o passado ou ele tivesse vindo para o futuro ao meu encontro. E também pelo fato de que ao olhar para uma foto ele se espantava, assim como tantas vezes eu me espantei. A diferença é que eu não tinha idéia da intensidade de reflexões que poderiam surgir a partir dessa sensação de estranhamento. Daí é que me pergunto: como ele Revista Digital de Ensino de Filosofia - Santa Maria - vol.2., n.2 - jul./dez. 2016. 
conseguiu ter essas ideias tão interessantes? Que caminho percorreu para ter sido a pessoa que foi e escrito este livro? São perguntas muito difíceis.

Barthes, além de ter escrito muito bem, colocou no livro algumas fotos que mexiam com ele, que de alguma forma despertava a imaginação e curiosidade. [...] E foi em uma dessas fotos que encontrei você Ernest. Você está lá na página 126. Não sei se lembra, mas quem tirou sua foto foi 0 fotógrafo Kertész em Paris no ano de 1931. A sala de aula, o lugar onde foi feita a foto, tem carteiras de madeira e os casacos pendurados em último plano demonstram que era um dia frio. Já era inverno Ernest? Imagino que não, pois você não estaria de bermuda. Mas não é ao espaço que meu olhar e imaginação se prendem. Por uns bons dias tentei diferenciar o seu olhar da menina do segundo plano. São tão diferentes!

Está curioso para saber o que Roland Barthes escreveu sobre você? Em 1979, ano em que escreveu o livro, ele se perguntava muito se era possível você estar vivo. Mas isso não é o que me preocupa. Pelas minhas contas hoje 17/08/2011 você pode estar mais ou menos com 86 anos. Não me esforço para pensar no que se tornou e onde está agora. Queria conhecê-lo assim como meus olhos alcançam: criança de semblante tranquilo e com uma das mãos levemente posicionada na carteira. Suas mãos! Como é possível um garoto da sua idade se expressar de forma tão intensa com elas. Para mim é um mistério o que os seus dedos querem dizer com a flexão que fazem em contraste com o tom escuro de sua roupa. Tento encontrar as palavras, mas não consigo.

Fico me perguntando quais são suas brincadeiras favoritas, a roupa que não gosta e a comida que te deixa enjoado. De alguma forma quero me encontrar criança na sua infância. Essa é a única carta que Ihe escrevo, mas sei que dedicarei meu olhar ao seu por um bom tempo. 


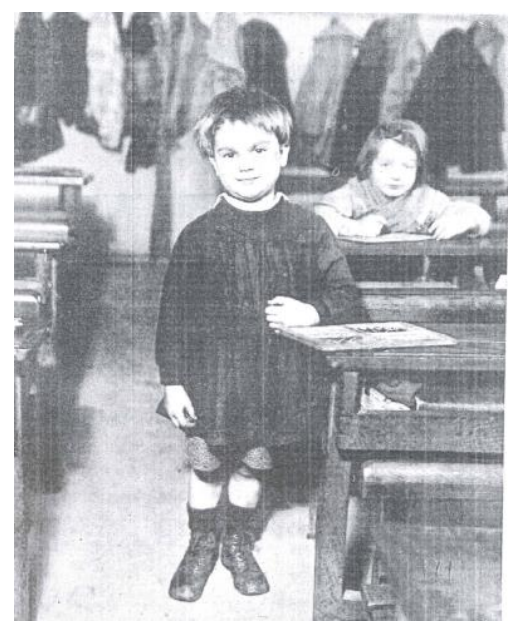

Figura 1: "Au revoir!" Cesira Elisa. 17/08/2011

Na aula marcada cada aluno traz sua foto revelada, colocando-a no chão da sala. Um deles dá início à atividade que consistirá na escolha de uma foto. Pergunta-se pelo autor e, na sequência, todos pensarão em um título para ela. O exercício segue deste modo, propondo o desafio de procurarem um título que consiga promover uma abertura no pensamento, potencializando os sentidos da imagem fotografada e dando densidade a eles. Por exemplo: se um título como "lugar" é proposto, talvez a palavra "lugares" seja mais potente para um alargamento das possibilidades de pensamento. O que é um lugare Um lugar pode ser algo diferente que um espaço? Quantos lugares encontro nessa imagem? As questões vão surgindo com os títulos propostos e com a discussão. O professor terá papel fundamental na atividade, pois nem sempre haverá consenso, mas isso é bom. É interessante pedir para o autor da foto um breve comentário sobre ela e o título escolhido pela turma. A foto continua a ser do aluno, mas as leituras somaram-se a ela, tornando-se experiência para outros também.

Sugerimos que essa atividade com fotos tenha prosseguimento com novo pedido aos alunos: o de fazer uma foto buscando a infância sem que a imagem seja a de uma criança. O professor pode pedir para que façam essa foto em grupo ou individualmente. Na aula marcada (que pode ou não ser na mesma, mas o tempo pode ser pouco) todos os grupos ou alunos(as) devem apresentar a sua foto e os demais dizem onde veem infância nela; somente em seguida os que a tiraram usam a palavra. A turma pode, ao final, escolher Revista Digital de Ensino de Filosofia - Santa Maria - vol.2., n.2 - jul./dez. 2016. 
uma que represente melhor uma ideia de infância para a maioria, escolhendo um título para ela através do mesmo exercício de ampliação de pensamento.

O que se pretende com essas aulas é deixar brotar em cada um o início de um filosofar como um olhar "primeiro" sobre o mundo, um começo, uma novidade e, portanto, como uma infância de um filosofar, assim como também um problematização e construção do conceito de infância e, portanto, de modo a permitir uma incursão pela Filosofia da infância.

\section{Ełapa 2: Experiência poética e experiência filosófica}

\section{"As quatro gares"12}

Oswald de Andrade (1890-1954)

\section{Infância}

O camisolão

O jarro

O passarinho

O oceano

A visita na casa que a gente sentava no sofá

\section{Adolescência}

Aquele amor

Nem me fale

\section{Maturidade}

O Sr. e a Sr. Amadeu

Participam a VExa.

O feliz nascimento

De sua filha

Gilberta

12 ANDRADE, Oswald de. Primeiro caderno do aluno de poesia Oswald de Andrade. São Paulo: Globo, 2006. p. 49-50.

Revista Digital de Ensino de Filosofia - Santa Maria - vol.2., n.2 - jul./dez. 2016. 


\section{Velhice}

O menino jogou o óculos

Na latrina

A experiência humana tem sido compreendida de diversos modos ao longo dos séculos, abrangendo tanto dimensões mais objetivas - como, por exemplo, a sociedade em que estamos e o tempo em que vivemos - até outras mais subjetivas - que dependem de um jeito particular de viver e de como esse jeito vai compondo e sendo composto pela história de cada um e combinando-se com esses elementos mais objetivos.

Em nossas sociedades predomina uma concepção linear que coloca uma etapa da vida como separada das demais. Essa concepção pode ser interessante para percebermos certas regularidades e similaridades que existem na vida de todos nós desde a infância até a velhice, mas ela também pode ser responsável por muitos reducionismos e estreitamento na compreensão da experiência dos seres humanos.

Em "As quatro gares", poema que se encontra no livro "O primeiro caderno de poesia do aluno Oswald de Andrade", temos um exercício poético do autor de voltar-se para cada uma destas "estações da vida".

Ler um poema pode ser uma experiência de leitura ou, mais ainda, uma experiência poética, mas se a partir dela nascem questionamentos, também pode nascer uma experiência filosófica. É o que proporemos a seguir: um exercício de desconstrução inspirado no poema acima. Ou seja: o exercício consiste em um olhar filosófico sobre a infância. Mas antes, vamos compreender melhor a ideia desconstrução.

A ideia de desconstrução está presente nas obras do filósofo franco argelino Jacques Derrida (1930 - 2004). Seu pensamento nos oferece uma estratégia que, partindo daquilo que é familiar, próximo, permite chegar ao seu avesso, rumo à sua ambivalência. Exercitar um olhar alheio ao mundo é aceitar abandonar a segurança. O mundo não pode mais ser visto como uma casa e, portanto, não há como "estar plenamente em casa" no mundo - eis que o estranhamento se mescla ao familiar. O papel da desconstrução, então, 
seria o de questionar os limites, as margens, as divisões arbitrárias, e abrir caminho para expor como toda a identidade é permeada pela alteridade. A desconstrução seria, antes de qualquer coisa, uma operação cujo efeito enaltece a emergência da alteridade. Trata-se de um movimento que, oposto à metafísica, abre-se ao Outro, ao advento da existência de um rosto estranho, estrangeiro.

É permeando as inquietações provocadas pela desconstrução derridiana, cuja desfamiliarização do olhar sobre um determinado objeto pode torná-lo singular, que se impele a epifania do Outro. O outro aqui tomado de todo um nomadismo, estranhamento e não pertencimento, que vem e coloca a sua questão, perturba, estremece o dogmatismo e que, por efeito da (im)previsível acolhida que se abre ao seu infinito ou ao infinitamente outro como outro que interrompe a si mesmo, faz nascer a questão da hospitalidade como princípio da ética. Para Derrida, a hospitalidade, que deve ser sempre incondicional, é uma prática mediadora da humanidade do homem.

Acolher o Outro é receber além da capacidade do acolhimento, e acolher além daquilo que é possivel acolher; é ultrapassar a recepção do convidado, pois deste sabemos a hora e o momento da sua chegada. $O$ acolhimento imediato, sem preparo, na urgência de um instante, requer prostrar-se ao Outro, estrangeiro, visitante sem aviso, pois ele é o recémchegado e acolhê-lo sem limites é o imperativo da hospitalidade incondicional, sem the questionar o nome, a origem ou a descendência. Desta forma, este Outro não é outro que eu possa compreender pela empatia. Ele é sempre um mistério, um rastro.

Agora vamos ao exercício que é, justamente, buscar uma desconstrução da concepção linear de infância começando com o reconhecimento de que às vezes vemos em nós a presença de elementos que seriam mais característicos de outras fases da vida do que na que vivemos no momento. Em seguida, reflita e escreva acerca das seguintes questões:

- O que há de infância, maturidade e/ou velhice em você? 
- O que falta de juventude em você?

- Pense na sua infância e depois escreva se vê nela uma mescla de elementos de outras fases da vida.

- Como podemos acolher e hospedar esses outros elementos, em nós e nos outros, de forma a tornar nossa experiência humana melhor?

- Por último, e considerando as suas respostas, elabore uma poesia com a mesma estrutura de "As quatro gares", de Oswald de Andrade.

O professor então pede para que a turma forme um círculo e convida um aluno para começar a comentar os seus exercícios de escrita, desencadeando um debate sobre as etapas da vida na experiência humana.

Derrida pertenceu a um grupo de pensadores franceses que em meados de 1960 passaram a ser denominados de "pós-estruturalistas". A denominação deu-se ao questionamento por eles desenvolvido sobre uma abertura para além do estruturalismo, assinalando seus limites e suas fronteiras. Este movimento utilizava-se da noção de estrutura para colocar em questão, sobretudo não em negação, as premissas do próprio estruturalismo. Derrida, então, seguindo a perspectiva pós-estruturalista, investigou, sob a luz dos aspectos do método estrutural, as relações e facetas do conceito de diferença para, assim, apontar os pressupostos metafísicos ora superados no estruturalismo. Surge no pensamento derridiano o questionamento da filosofia como uma interrogação da sua real possibilidade. De acordo com Derrida, qualquer tentativa de estabelecer a verdade é metafísica, o que invoca determinada presença. Assim, desconstruir é herdar para além do que pretende legar o próprio texto, ou a linguagem, ou a ideia e, em um movimento de fidelidade infiel, realizar um processo de descentramento do pensamento, da historicidade, do psiquismo. Desta maneira, aceitar Derrida, é uma tentativa de pensar o limite do conceito, resistindo à experiência e a excedendo.

\section{Etapa 3: Lugares da Filosofia e da infância}

Título? "Crônica". Crônica? "Era uma vez o mundo"13. Uma única e

13 ANDRADE, Oswald de. Primeiro caderno do aluno de poesia Oswald de Andrade. São Paulo: Globo, 2006. p. 70.

Revista Digital de Ensino de Filosofia - Santa Maria - vol.2., n.2 - jul./dez. 2016. 
genial frase. A quais sentidos remete essa crônica espetacular de Oswald de Andrade? É o início de uma narrativa? É uma narrativa completa? Remete ao começo do mundo? Ao seu fim? Tudo junto talvez, e certamente outros sentidos mais que pedem para serem descobertos. Aliás, falar pouco, mas com frases potentes, talvez seja um dos modos de potencializar sentidos, descobrir ideias que parecem encobertas.

Heráclito (535 a.C. - 475 a.C., aproximadamente), conhecido também como o "obscuro", nos deixou uma miríade de sentidos a serem des-cobertos em seus fragmentos de uma obra intitulada "Sobre a Natureza". Abaixo temos alguns deles e uma pintura de Cesira Elisa de Fávari. Em primeiro lugar, leia atentamente os fragmentos.

\section{FRAGMENTOS DE HERÁCLITO14:}

8) Tudo se faz por contraste; da luta dos contrários nasce a mais bela harmonia.

10) Correlações: completo e incompleto, concorde e discorde, harmonia e desarmonia, e de todas as coisas, um, e de um, todas as coisas.

35) De muitas coisas devem homens amantes da sabedoria estar avisados.

41) Só uma coisa é sábia: conhecer o pensamento que governa tudo através de tudo.

47) Não devemos julgar apressadamente as grandes coisas.

51) Eles não compreendem como, separando-se, podem harmonizar-se: harmonia de forças contrárias, como o arco e a lira.

52) O tempo é uma criança que brinca, movendo as pedras do jogo para lá e para cá; governo de criança.

54) A harmonia invisível é mais forte que a visível.

14 BORNHEIM, Gerd A. (org.). Os filósofos pré-socráticos. São Paulo: Ed. Cultrix, 2007. p. 36-43.

Revista Digital de Ensino de Filosofia - Santa Maria - vol.2., n.2 - jul./dez. 2016. 
70) (Dizia que as opiniões dos homens são) jogos de crianças.

79) O homem é infantil frente à divindade, assim como a criança frente ao homem.

101) Eu me procurei a mim próprio.

112) O bem pensar é a mais alta virtude; e a sabedoria consiste em dizer a verdade e em agir conforme a natureza, ouvindo a sua voz.

113) O pensamento é comum a todos.

116) A todos os homens é permitido o conhecimento de si mesmos e o pensamento correto.

124) A mais bela harmonia cósmica é semelhante a um monte de coisas atiradas.

Escolha um que você tenha achado mais interessante e invente um fragmento inspirado nele (com o mesmo sentido/conteúdo ou com a mesma estrutura). Depois elabore um texto contando o que pensou quando criou $o$ fragmento.

Sigamos agora para a pintura. Contemple-a. Observe suas partes e seu conjunto.

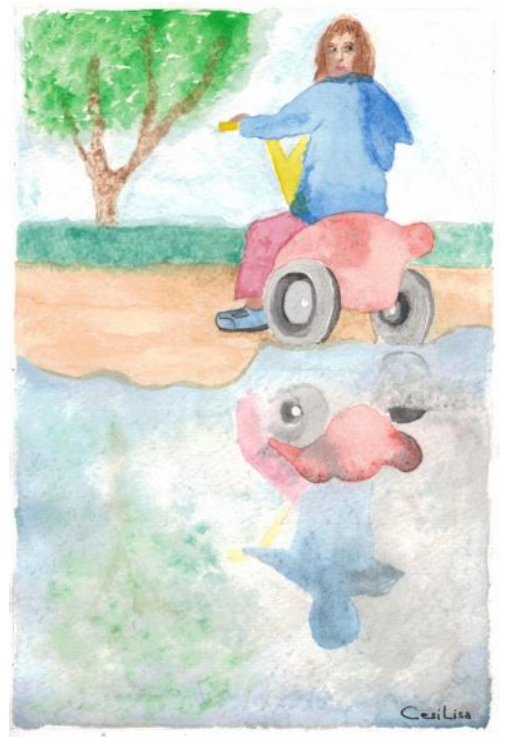

Figura 2 
O que você vê? $\mathrm{O}$ que as imagens podem nos dizer sobre o mundo quando comparadas às palavras? Escreva sobre essa experiência, procurando filosofar, mostrando a sua leitura desse quadro para si mesmo(a) e para o outro. Pergunte-se: Em qual(is) lugar(es) encontro Filosofia? Em qual(is) lugar(es) encontro Infância? Há algum/alguns lugar(es) em que Filosofia e infância se encontram nesse quadro? Comece com uma ideia chave, uma espécie de tese a ser defendida. Quando terminar veja mais uma vez a pintura e vá novamente até os fragmentos de Heráclito, procurando escolher aquele que mais combina com o que escreveu sobre a imagem.

O professor poderá dar prosseguimento à aula pedindo para que os alunos comecem a mostrar aos demais o que escreveram ou o que pensaram dessas duas atividades.

\section{Referências}

ANTUNES, Arnaldo; ANTUNES, Tomé Moreau. Frases do Tomé aos três anos. Compilação e ilustração de Arnaldo Antunes. Porto Alegre: Alegoria, 2006.

ARIÈS, Philippe. História Social da Criança e da Família. Rio de Janeiro: LTC, 1981.

$\mathrm{COHN}$, Clarice. Uma análise da infância e do desenvolvimento infantil entre os Kayapó-Xikrin do Bacajá. Revista de Antropologia. v.43, n2, p.195-222, 2000.

$\mathrm{COHN}$, Clarice Antropologia da Criança. Rio de Janeiro: J. Zahar Editor, 2005.

EPICURO. Carta sobre a felicidade (A Meneceu). Tradução e apresentação de Álvaro Lorencini e Enzo Del Carratore. São Paulo: Ed. UNESP, 2002. 1987.

GEERTZ, Clifford. A interpretação das culturas. Rio de Janeiro: Zahar,

KOHAN, Walter Omar. A infância da educação: o conceito devircriança. In:

KOHAN, Walter Omar. (org.). Lugares da infância: filosofia. Rio de Janeiro: DP\&A, 2004. p. 51-68.

KOHAN, Walter Omar. Infância, estrangeiridade e ignorância: Ensaios de Filosofia e Educação. Belo Horizonte: Autêntica, 2007.

LARROSA, Jorge. O enigma da infância: ou o que vai do impossível ao 
verdadeiro. In: Pedagogia profana: danças, piruetas e mascaradas. Tradução de Alfredo Veiga-Neto. Belo Horizonte: Autêntica, 2003. p. 183-198.

MONTAIGNE, Michel de. Ensaios: uma seleção. Organização de M.A. Screech. Tradução e notas de Rosa Freire D’Aguiar. São Paulo: Cia. das Letras, 2010.

POSTMAN, Neil. O Desaparecimento da Infância. Tradução de Suzana Menescal de Alencar Carvalho e José Laurenio de Melo. Rio de Janeiro: Graphia, 1999. 